$$
\begin{aligned}
& F(07-9 / 10 / 3078 \\
& D 06 / I D \mid 13078-T 2
\end{aligned}
$$

\title{
Department of Energy \\ Electric and Hybrid Vehicle Site Operator \\ Program \\ at Pacific Gas and Electric Company
}

Final Report

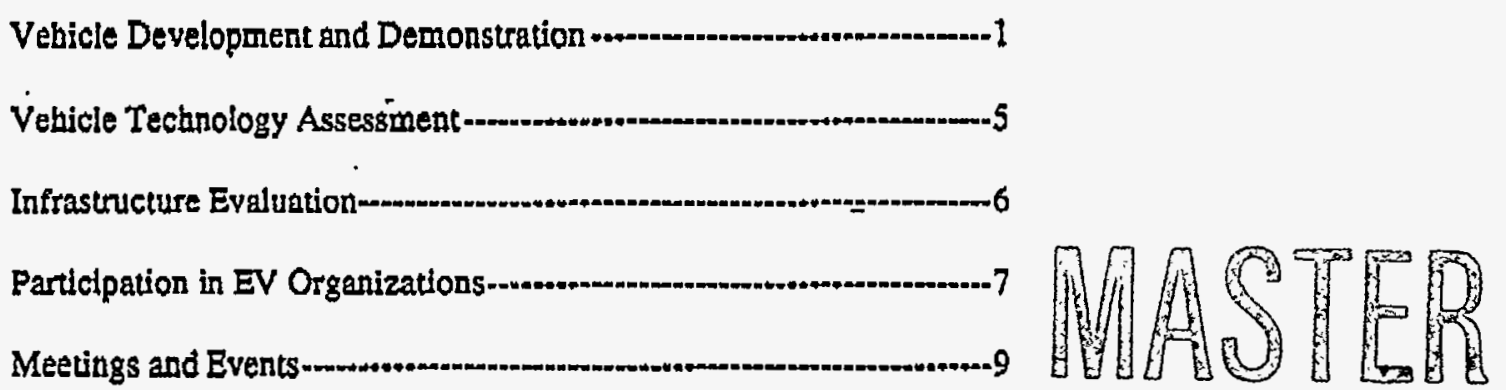

DISCLAIMER

This report was prepared as an account of work sponsored by an agency of the United States Government. Neither the United States Gnvernment nor any agency thereof, nor any of their employees, makes any warranty, express or implied, or assumes any legal liability or responsibility for the accuracy, completeness, or usefulness of any information, apparatus, product, or process disclosed, or represents that its use would not infringe privately owned rights. Reference herein to any specific commercial product, process, or service by trade name, trademark, manufacturer, or otherwise does not necessarily constitute or imply its endorsement, recommendation, or favoring by the United States Government or any agency thereof. The views and opinions of authors expressed herein do not necessarily state or reflect those of the United States Government or any agency thereof. 


\section{DISCLAIMIER}

Portions of this document may be illegible in electronic image products. Images are produced from the best available original document. 


\section{EV Activities at Pacific Gas \& Electric}

Pacific Gas \& Electric Company continues to expand an EV program that addresses the following:

- Vebicle Development and Demonstration

- Vehicle Technology Assessment

- Infristructure Evaluation

- Participation in EV Organizations

- Meetings and Events

This report highlights PG\&E's actlvites in each of these areas:

\section{Vehicle Development and Demonstration}

Fleet Electric Vehicles and Narrow Lane Vehicles

In a Joint project with CaITrans and others, PG\&E contracted with Motive, Inc., to develop two new types of EVS: a Fleet Electric Vehicle (FEV) and a Narrow Lane Vehicle (NLV). The project, which begant in the second half of 1992, enhanced development of the FEVwhich looks like a small van and can haul moderate loads. The vehicle, targeted at in-town delivery fleets, was shown to the Postal Service in September 1995 and was displayed at auto shows throughout 1996. The vehicle is currently in operational checkout by Motive. The fabrication of five more FEVs will continue in 1997. Delco has suggested use of the GM Impact transmission/motor In the FEV; this prospect, as well as other drive system technologies will be evaluated in 1997.

PG\&E actively participated in Phases I and II of the program- the vehicle design and creation of a prototype. Although PG\&E is not currently participating in the program, they will have priority in future demonstrations of the FEVs.

The NLV, a new class of vehicle no wider than 52 inches, is intended to ease congestion by allowing CalTrans to divide a single lane in two. Motive's design for this vehicle is a tandem configuration with the passenger located behind the driver In a cockpit-like shell. This project expertenced some delays due to a change of subcontractor. However, the flrst NLV, designed to run on compressed natural gas (CNG), is $95 \%$ complete, and the electric-powered NLV is 50\% complete. PG\&E. in conjunction with outside developers, intends to begin NLV road trials by the latter half of 1997.

Ecostar Operation

PG\&E operated flve all-electric Ford Ecostars during the first half of 1996. They were used throughout the service territory by meter readers, customer service representatives, electrical inspectors, parts delivery personnel, and staff commuters. The Ecostars were typically charged at the service center at $240 \mathrm{~V}$, although the vehicles were occasionally slow charged at home by PG\&E employees at $110 \mathrm{~V}$. The $90+$ mile range and $70 \mathrm{mph}$ top speed have made the minlvans popular throughout the service territory. The vehicle was to be tested in the first quarter of 1996 at Clean Air Vehicle Technology Center (CAVTC). However, operational problems were experienced. Testing was then discontinued, and Ford installed a 
new battery pack. In the second quarter of 1996, successful evaluations of range, acceleration rates at different states-of charge, and charge time were conducted. In June 1996 , the program was completed, and all five Ecostars were returned to the manufacturer.

Hondas

In the frst half of 1996, PG\&E operated three Honda EVs for demonstrations and fleet use. The vehicles-equipped with lead acld battertes-achleved 35-40 miles per charge. The vehicles operated with zero failures throughout this time period requlring only regularly scheduled preventlve maintenance. Two of the three vehicles were then retumed to Honda at the end of the second quarter in exchange for a Honda Civic-Natural Gas Vehicle (NGV). to be dellvered to PG\&E in 1997. The remaining Honde was modified with a tickel metal hydride battery pack and returned to PG\&E durng the second of quarter 1996. Under the Electric Vehicle Technology Evaluation Program, which began in November 1995, this vehlcle was successfully tested at CAVTC to characterize its performance, as well as to provide feedback to the manufacurer.

\section{Chery S-10s}

PG\&E is in possession of flve electric-powered Chevy $\$-10$ pickup trucks, obtained from U.S. Electricar. The trucks were used throughout the year for miscellaneous tasks such as "meter reading and parts pickup.

In the first quarter of 1996, FG\&E began retrofiting the flve pickups with different EV components. The third and fourth quarters were to mark the completion of many of the new technology installations, however several technical problems developed. A Wavedriver controller/charger was to be instailed in one pickup in September 1996. Due to operational difficulties, the system could not successfully recogntze the battery technology, Various software and E-Prom problems were experienced as well. As a result, completion of the Wavedriver installation was further delayed to the end of 1996. A $5 \mathrm{~kW}$ Coherent Power charger-dest gned to recondition on-board batteries-was to be installed into a second vehicle in the third quarter as well. Unfortunately $P G \& E$ was forced to redesign the circuitry to prevent the charger from overcharging the batteries. Charger testing is expected to begin in December. The Hawker batteries in a third tuck were to be replaced with an Electrosource Horizon battery pack and a Badicheq battery management system (BMS) with the overall intention of modifying the technology to accept power from a Wavedriver charget. Due to technical difficulties, the Badicheq BMS was sent back to the manufacturer for repair. A new E-Prom was installed in November, and completion of the vehicle retrofit is expected for early 1997. The fourth truck will receive a Hughes charger upon delivery from the manufacturer, while the fifth will receive new components to be determined in 1997.

All of the U.S. Electricar S1OS will be tested under the Electric Vehicle Technology Evaluation Program by PG\&E and CAVTC staff in 1997.

\section{Toyota RAV4}

In the first quarter of 1996, PG\&E received a Toyota RAV4-EV, the electric-powered version of Toyota's sport-utility vehicles, PG\&E and other electric utilities are testing a total of seven RAV4-EVs over the next two years under a wide variety of operating conditions. Since its arrival, the vehicle was used regularly for demonstrations and fleet applications without any problems. During the third quarter an on-board $\mathrm{kWh}$ meter was 
installed, and was used in 1996 to quantify energy consumption. This program will continue in 1997.

Table 1 describes the number of miles each vehicle was driven through Octuber 1996.

Table 1 * Prototype Electric Vehicle Mlleage per Month

\begin{tabular}{|c|c|c|c|c|c|c|c|c|c|c|c|}
\hline & & & & & & Veh & $e^{*}$ & & & & \\
\hline & & & $E \cos$ & & & & EOB & a Clye & & Toyota & TOTAL \\
\hline Monch & $\$ 006$ & $\# 034$ & 4035 & $\$ 037$ & $\$ 038$ & \#013 & $\$ 015$ & $4016=4$ & 417 & RAV4 & \\
\hline January & & & 256 & & 928 & 165 & 196 & 234 & & 98 & 1877 \\
\hline February & & & 148 & & 154 & 67 & 377 & 198 & & $\$ 49$ & 1493 \\
\hline March & & 197 & 311 & 350 & & 65 & 108 & 559 & & 233 & 1823 \\
\hline April & & 293 & 247 & 507 & & & 114 & 451 & & 453 & 2063 \\
\hline May & 810 & 867 & & & & & 93 & 503 & & 943 & 3218 \\
\hline Juno & End $* *$ & End $*$ & End *** & Ind *n* & End $* 4$ & & 202 & & 655 & 976 & 1833 \\
\hline July & & & & & & & 352 & 670 & 548 & & 1570 \\
\hline August & & & & & & & 3,53 & 719 & 522 & 429 & 2023 \\
\hline Septearber & & & & & & & 274 & 467 & 234 & $85 !$ & 1826 \\
\hline Octobar & & & & & & & 222 & 474 & 11 & 312 & 1029 \\
\hline Noveriber & & & & & & & $E_{n d} \times$ & & End $* *$ & & \\
\hline Total & 810 & 1357 & $\overrightarrow{962}$ & $\overrightarrow{857}$ & 1082 & 297 & 2191 & 4223 & 2030 & 4844 & 18753 \\
\hline
\end{tabular}

Bay Area Station Car Demonstration

PG\&E is working with the Bay Area Air Quality Management District (BAAQMD), Bay

Area Rapid Transit (BART), and other groups to demonstrate "starion cars." The cars are lensed to local business employees and are driven berween their residences and BART stations, between BART and work, and on daytime errands. Leasing costs are estimated at $\$ 100-\$ 150$ per month plus insurance; mainterance and emergency road service are included in the fee. The project employed a Norwegian car, the Citi by PIVCO (Personal independent Vehicle Co.). Twenty two vehicles are curently in operation; most are leased by employees of Sybase (an Emeryville software company) and Bank of America. The program included a total of forty vehicles by the fourth quarter of 1996 . The demonstration will continue through 1997.

In October 1995, PG\&E installed charging stations at the Ashby BART station in Berkeley to provide $120 \mathrm{~V}$ or $208 \mathrm{~V}$ charging for up to 19 vehicles. Designed to allow for home charging, these vehicles were targeted at local business employees to be driven between their residences and BART stations, BART and work, or on daytime errands. Two vehicles, placed at BART headquarters, operated successfully throughout the year. The Ashby station program currently serves 7 vehicles. The goal is to serve a total of 13 vehicies at this station by the end of 1996. The Colma BART station work was completed in the third quarter. and now successfully serves a total of 11 vehicles. Construction to accommodate a total of 8 PIVCO vehicles at the Walnut Creek BART station was completed in October. This station currently serves 3 vehicles, yet expects to receive 5 additional PIVCO vehicles by year end. 


\section{Xosemite Shuttle Buses}

PG\&E continued to work with Yosemite National Park and its concessionaire, CalTrans, the Califomia Energy Commission, and Hughes Power Control Systems in the demonstration of electric shuttle buses in Yosemite Valley. The buses were delivered during the first quarter of 1996. One bus, butl by Specialty Vehicle Manufacnuring in Downey, CA, has a 31 -foot traditional steel and tiberglass body, a low-floor design for wheelchair access, and capacity for up to 32 passengers. The other bus, built by APS Systems of Oxnard, CA, is a 35-100t advanced technology vehicie using composite materials. Both buses used Trojan quickchange battery packs. Installation of the dinta acquisitlon system is scheduled for January 1997.

Vehicle testing, data collection, and route evaluation were conducted on the Specialty Vehicle Manufacturing bus this year, and will continue for the 6 to 9 months. However, in the first quarter of 1996 . the second bus was returned to APS Systems to repair operational problems. The bus was supposed to be returned to Yosemite in May of this year. Unfortunately, further operational problems were experienced and the date of delivery has been postponed indefinitely.

\section{Fresno Passenger Bus}

-A 22-foot U.S. Electricar passenger bus, located in Fresno was used as a lunchtime shuutle, and for group transport by arangement. It did not experience any fallures and the program was successfully completed in August. In the fourth quarter of 1996, the bus was moved to San Jose's Public Transportation deparment where the power steering pump and motor failed. Incorrect sizing of the power steering pulleys cause the pump to operate at excessive speeds. Both components were successfully repared in December and the program is expected to continuse through the second quarter of 1997.

\section{Electric Shuttle Buses in Berkeley}

PG\&E continues its involvement with the seven 22-foot U.S. Electricar shuttle buses in Berkeley. Four of these belong to the University of Califomia; the other three were procured by the Berkeley Gateway Transportatton Management Agency (TMA), a group established by local employers, with oversight provlded by the City of Berkeley, to encourage Increased use of public transit by providing four electric shuttle buses from the Berkeley BART station to businesses in West Berkeley. Both fleets are operated and maintained by the University. which provides central charging facilities. In November 1995, four of the buses began provlding mid-day hollday shuttle service for shoppers in downtown Oakland. The service is expected to be extended through May 1997.

The combined use of these buses for commercial and public transport has forced the Berkeley Gateway TMA to charge some of the vehicles during peak hours. In an effort to reduce costs, the TMA is currently negotiating wlth PG\&E, which continues to participate in this program through on-call support, to provide automated charging technology in 1997.

\section{Hybrid Electric Bus Demonstration}

PG\&E Is actively participating in CAISTART's hybrid electric bus project with the Santa Barbara County Air Pollution Control District (SBCAPCD). The objectives are to advance EV and CNG technology on heavy-duty vehicles, test power system and bus component technologies, and provide air quality benefits. 
Three military buses (two for 44 passengers and one for 88 passengers), retrofitted with hybrid propulsion systems from APS, operated in the first quarter of 1996 at Vandenberg AFB. The program was officially completed in April 1996. Because the performance by these buses in key criteria, such as range, top speed, and gradeability, was lower than expected, Vandenberg AFB no longer wishes to operate the vehlcles. Santa Barbara Metropolitan Transit Department is currently negotiating to assume responsibility for the vehicles in 1997.

Two additional buses are planned for the demonstration. One full-size (40-foot) transit bus is being built from the ground-up by APS. Many of the major components have been procured, and the bus frame is partially constructed. However, the motor has yet to be installed. Completion of the second 40-foot hybrid electric bus was delayed when the drive manufacturer (FMC) pulled out of the project. The Technicat Advisory Comnittes which met in the first quarter of 1996 to discuss performance issues with the Vandenberg AFB buses, has adjusted the timeline for work on the two additional buses, which are now to be completed by the end of 1996, or early 1997.

G.Van Operation and Evaluation PG\&E possessed three electric G-Vans in 1996. Two were in San Luis Obispo, where they were used for Phase 3 of the Rapid Battery Interchange Frogram with Cal Poly State University. In the first quarter of 1996, Col Poly was in negotation with PG\&E to lease and eventually owin the G-Vans as part of the project. In the third quarter, PG\&E elected to donate the vehicles to Cal Poly for research puposes. The City of Santa Rosa is currently negotiating with PG\&E to purchase the third vehicle in 1997.

\section{Data Collection for Other Fleets}

PG\&E helped various customers in its service territory monitor the performance of their EVs and charging equipment. In the first quarter of 1996, PG\&E established a data meter for San Francisco State University, where fleet operators are monitoring energy consumption. Summary reports describing energy and vehlcle usage data were delivered to PG\&E on a quarterly basis. PG\&E also continued discussions with the city of Solvang to determine a lucation for a charging station and operation of an electric bus. An outslde contractor will deliver the charging facility at a date to be determined.

\section{Vehicle and Technology Assessment}

Electric Vehicle Technology Evaluation

PG\&E, In combination with Bevilacqua Knight Inc. (BKI) and the Clean Alr Vehlcle Technology Center (CAVTC), continued a dual purpose ongoing evaluation program-that began in November 1995-with the testing of a Ford, and a Honda, and continued with the testing of 4 additional protorype electric vehicles. This performance and technology analysis was designed to serve many objectives. First, a series of standard test protocols for EV perfomance evaluation were developed. Second, several prototype EVs were examined to help determine their suitability for fleet appllcations. Finally, vehicle laboratory and realworld performance feedback will be provided to original equipment manufacturers (OEMs). As a tesult of this work. PG\&E will be better equlpped to evaluate EVs for internal, and 
ultimately external fleet use, while OEMs will recelve information to improve EV technology for fleet application.

This program will continue into 1997 with the testing of flve U.S. Electricar $\$ 10$ s outtlted with various charger and battery technologies.

Examples of first and second quarter laboratory test results for three vehicles is as follows.

\section{EV \#1}

This Vehicle was tested at CAVTC in April 1996. Using Hawker lead acid batteries, and a Hughes charger, this prototype achieved an average range of approximately 30 miles. The vehicle averaged 1,48 miles/ $\mathrm{kWh}$, and suffered a $26 \%$ reduction in energy efficiency with use of the auxiliary system. Acceleration from 0 to $60 \mathrm{mph}-$ at the maximum (100\%) state-ofcharge (SOC) - was completed in approximately 35 seconds. At the minimum state of charge ( $30 \%$ SOC), the car reached 60 moh in approximately 40 seconds. In several instances, acceleration tests at $30 \%$ could not be completed before the SOC fell to $20 \%$. In these instances testing was aborted, and the vehicle was recharged for the next sequence. Despite minor complications, valuable performance data were collected for the vehicle.

\section{$-\mathrm{EV}$ \#2}

This vehicle was tested in April and May 1996. Powered by a nickel metal hydride battery, the vehicle achieved an average range of 77 miles. Also noteworthy, of the 5 different vehicle types tested, this vehicle achieved the greatest range with auxiliary system use. Energy consumption averaged at 2.2 miles/kWh, and the reduction in energy efficiency with auxillary system use was approximately $9 \%$. The vehicle accelerated from 0 to $60 \mathrm{mph}$ in approximately 19 seconds at both the maximum (100\%) and minimum (30\%) SOCs.

\section{$E V \# 3$}

This yehicle was tested in May 1996. Due to battery failure, the iritial test sequence-conducted in November 1995 - could not be completed. Despite these earlier problems, the vehicie performed well in the subsequent evaluation. Powered by a sodium sulfur battery, the vehicle achleved an average range of approximately 77 miles. Without auxiliary system use, the vehicle achieved a maximum range of approximately 92 miles. Energy consumption averaged at 2.2 miles $/ \mathrm{kWh}$, and the reduction in energy efuciency with auxiliary system use was approximately $41 \%$. The vehicle accelerated well, traveling from 0 to $60 \mathrm{mph}$ in approximately 20 seconds at $100 \%$ SOC and 22 seconds at $30 \%$ SOC.

\section{Infrastructure Evaluation}

\section{EMF Protocol Development}

In December 1994, PG\&E hired a subcontractor experienced in EMF measurement to revise the draft protocol into two levels. Level I provides basic characterization with hand-held meters, while Level II provides a much more extensive characterization. The prolocol was completed and is currenty under review for tinalization by the Load Management Comminee of the Infrastructure Working Council. 


\section{Fast Charge EV Test Facility}

PG\&E sponsors the EV Test Facility at CAVTC in Hayward, CA. PG\&E is currently writing the test protocols for a fast charger, to be delivered to CAVTC in 1997. The protocols were originally to be delivered in August of this year. However, the Electric Power Research Institute (EPRI) is currently working on similar protocols, and PG\&E has declded to analyze the outcome of this work as lnput to its own protocols.

\section{Rapid Battery Interchange Program}

The Rapid Battery Interchange Program at Califormia Polytechnic, sponsored by FG\&E, CaiTtans, and the Callfornla Energy Commission, is demonstrating an alternative recharging concept-the rapid automated exchange of battery gacks. The fully atutomated sites are intended to function much like conventional service stations. "Refueling" occurs in a matter of minutes through exchange of the vehicie's used battery packs for new, fully charged battery packs. Phase 3 of the Program-a full-scale, multi-vehicle road test-began in the toll of 1995 and is scheduled to be completed in 1997.

\section{Charger Technology}

Ongoing evaluation produced charger profiles on three vehicles. Two of the chargers had well-controlled profiles while the third exhibited a jagged charger proflle. It was thought that "this profile could affect customers and PG\&E's power quality. However, the profile was discovered to be the result of an improper connection within the onboard battery/charger system. PG\&E reported this finding to the EV manufacturer in the third quarter of 1996. Charger test protocois will be completed, and testing to evaluate power conversion factor, true and displacement power factor, total harmonic distortion, dc output ripple voitage, and magnetic nelds will begin in the first quarter of 1997.

\section{Participation in EV Organizations}

\section{Bay Area Fleet EVs User Group}

PG\&E continued to moderate a previously established informal user group comprising private and publlc organizations that own (or want to own) EVs. Group members include Bank of Amertca; the clties of Alameda, Berkeley, Emeryville, San Francisco, South San Francisco, and Napa; Alameda, Contra Costa, and Santa Clara counties; UC Davis; the federal GSA and the State Departrient of Generat Services; and the Bay Area Air Quality Management District.

\section{Infrastructure Working Councll}

The Infrastructure Working Council (IWC) brings together automakers, electric utilities, code speciallsts, and other EV stakeholders to promote development of a safe, reliable charging infrastructure. PG\&E chairs the Infrastructure Steering Committee (ISC)-a group directing the IWC-and serves on two working committees; Connectors and Connecting Stations, and Power Quallty and Load Management. The PG\&E representative to the ISC stepped down from this position, effective December 1996. 
Electric Vehicle Association of the Americas

PG\&E was active in the Electric Vehicle Asscxiation of the Amettcas (EVAA), serving on the Technical Advisory Review Committee to provide rapld response to misinformation regarding EVs and EV infrastructure issues. PG\&E is also part of EVAA's Infrastructure Readiness Tearn, created in preparation for the market launch of EVs.

National Station Car Association

A PG\&E representative served as Treasurer of the National Station Car Association. This group is organizing a natlonwide demonstration of 500 electric "station cars" for use between home and transit stations (rall or express bus). PG\&E is cosponsoring a demonstration of 40 of these cars at BART stations in the San Francisco Bay Area. Since 1993. PG\&E has played a major role in founding the association, and continued to provide the group with legal and technical assistance.

\section{Other Organizations}

PG\&E continued to be a member of the following organizations:

- United States Advanced Battery Consortum (USABC)

- Callforuia Electric Transportation Coalition (ETC); PG\&E's representative serves as Treasurer

- Clean Air Vehicle Technology Center (CAVTC) in Hayward, CA: PG\&E is CAVTC's principal corporate sponsor 


\section{Meetings and Events}

Throughout 1996, PG\&E met with a wide cange of organizations, as noted below.

January

9 - BAAQMD meeting to discuss EVNNGV development5

11 - Froject California/AAA meeting at CAVTC to discuss potential consumer repording for $E V S$

17 - EV Emergency Response Task Force meeting at the California Air Resources Board (CARB)

18 - Meeting with Toyota to prepare for arivival of RAV4-EV

22 - Meeting with Honda to discuss Honda's demonstration EVs

23 - Meeting with Tom Addison, BAAQMD, to discuss PG\&E's EV activities

25 - Site visit with U.S. Postal Service to discuss placement of a charger for an EV demonstration

31 - Electric Transportation Coalition (ETC)/Sacramento Municipal Utility District EV Market Launch Workshop in Sacramento

February

1 - BAAQMD meeting to discuss EVANGV developments

8 - PG\&E presentation on low emission vehicles at San Joaquin Valley Clear Alr Coallition

8 - Yosemite zero-emission bus project meeting

13-14 - Meeting in Detroit with Detroit Edison to discuss EV data interfaces

20 - Meeting at Electric Power Research Institute to discuss potentlal for electric aipport vehicles

21 - Advanced Lead-Acid Battery Conference in Sactamento

22 - Meeting with Wavedriver to Discuss Installation of Chargers on U,S. Electricar plck-ups

23 - PG\&E led an ETC - Coordinated Congressional fieid trip to Bay Area EV locations

27 - Meeting with Callfornia ETC to discuss strategic planning for 1996 and 1997

March

8 - Advanced Transportation Industry Meeting at CALSTART in Anaheim

$14 p$ - EV pianning meeting with the City of Davis and University of California, Davis

19 - EV Emergency Response Task Force meeting at CARB

April
16 - Project Callfomla meeting
18 - Electric Transpontation Board Meeting
23 - EVAA Board of Directors Meeting
24.25 - ETC Market Launch - Phoenix, Arizona 
May

$\begin{array}{ll}1 & \text { - UC Davis EV Charging Project Meeting } \\ 1 & \text { - Electric Bus Open House } \\ 2 & \text { - GM - Electric Vehicle Incentives Meeting } \\ 10 & \text { - Anerican Lung Association - Clean Air Vehicle Demonstration } \\ 14 & \text { - BAAQMD Meeting } \\ 16 & \text { - EV Building Codes Meeting } \\ 17 & \text { - Berketey Solutions Meeting - EVs for various uses } \\ 28 & \text { - Station Car Project Meeting } \\ 29 & \text { - City College of San Francisco - EV Presentation }\end{array}$

June

$\begin{array}{ll}6 & \text { - Station Car Demonstration Phone Conference } \\ 11 & \text { - BAAQMO Meeting } \\ 12 & \text { - EV Bullding Codes Workshop } \\ 18 & \text { - CEC Meeting - EV Charging and Bllling Issues } \\ 19 & \text { - EPRI - ZEB Workshop } \\ 20 & \text { - EV Public Charging Team Meeting } \\ 27 & \text { - Project Calfomia IVTIC Meeting }\end{array}$

July

10 - Berkeley Solution EV meeting

17 - Meeting in Fresno to discuss the operations of the electric passenger bus

18 - Meeting with Yosemlte National Park to discuss shuttie operations

22 - CALSTART dedication

25 - Clean Citles Forum

25 - EV market launch in Sacramento

31 - Honda EV Introduction Event

August

1 - Meeting with Public Charging Work Team

9 - Meeting with CalETC Billing Team

12 - EPA - Spare the Alr Event

13 - Toyota Event for EV Introduction

13 - Meeting of Concerned Scientsts

14 Meeting in Fresno to discuss electric bus operations

September
4-5 - Meeting to discuss Honda EV Demonstration Project
6 - San Francisco TMA Event - Toyota RAV4 Public Demonstration and Display
12 - Walnut Creek Charging Kiosk Contract Meeting
17 - Station Car - TAC
18 - Press Conference for Stanford EV Rally
19 - Fublic Charging Team meeting
20 - Billing Systems Team meeting
21 - Stanford EAA EV Rally 
22 - U.S. Electricar LT-02 Bus V1deo Taping for Operator Tralning Tape

October
$3^{\circ}$ - EV Warrior Trial
10 "Department of Energy EV Display
16 - EV Charging Meeting - Karen Hemphill, Emerywille
17 - CCEEB Meeting
22 - Inductlve Roadway Project
24 - Public Charging Team
30 - ZEB Taplng and Maintenance

November

13 - Toyota EV Demonstration

December
5 - Emergency Response Training
10 - EVAANSCA Board Meeting
11 - NAEVI 96 Tutorial: The Basics of EVs 